\title{
Effect of Hygrothermal Treatment on Reliability of Thermo-Compression Bonded FPCB/RPCB Contact Joints
}

\author{
Jeong-Won Yoon ${ }^{1, *}$ and Seung-Boo Jung ${ }^{2, *}$ \\ ${ }^{1}$ Micro-Joining Center, Korea Institute of Industrial Technology (KITECH), 156 Gaetbeol-ro, Yeonsu-gu, Incheon, Korea \\ ${ }^{2}$ School of Advanced Materials Science and Engineering, Sungkyunkwan University, \\ 2066 Seobu-ro, Jangan-gu, Suwon, Gyeonggi-do, Korea
}

\begin{abstract}
In this study, electrodes on a flexible printed circuit board (FPCB) and rigid printed circuit board (RPCB) were bonded together by thermo-compression (TC) bonding, using a Sn-3.0Ag- $0.5 \mathrm{Cu}$ solder as an interlayer. In order to investigate the hygrothermal reliability of the TC bonded FPCB/RPCB joints, a temperature-humidity (TH) test of $85^{\circ} \mathrm{C} / 85 \%$ relative humidity, and a $90^{\circ}$ peel test, were conducted. The relationships between the TH treatment, peel strength, and failure analysis result were discussed. The peel strength significantly decreased as TH time increased. In contrast, a significant variation in electrical resistance was not observed during TH testing. Thin and uniform $\left(\mathrm{Ni}_{1} \mathrm{Cu}\right)_{3} \mathrm{Sn}_{4}$ intermetallic compound (IMC) layers were formed at both FPCB $/ \mathrm{Sn}-3.0 \mathrm{Ag}-0.5 \mathrm{Cu} / \mathrm{RPCB}$ interfaces. After a TH test for $500 \mathrm{~h}$, the thickness of the IMC layer was slightly increased. In the case of the joint without TH treatment, a fracture occurred at the polyimide of the FPCB. After the TH test, the degradation of the adhesion between the polyimide and $\mathrm{Cu}$ in the FPCB occurred, due to the hygrothermal treatment, resulting in a switch of failure mode, from a polyimide failure to a brittle polyimide/Cu interface failure. X-ray photoelectron spectroscopy (XPS) analyses showed that the decrease in $\mathrm{C}-\mathrm{O}$ and $\mathrm{C}=\mathrm{O}$ bond ratios caused a decrease in peel strength of the TC bonded FPCB-RPCB joints, after the TH test. When comparing the TH and HTS tests, the TH test significantly deteriorated the integrity of the TC bonded FPCB-RPCB joints. [doi:10.2320/matertrans.M2016006]
\end{abstract}

(Received January 6, 2016; Accepted February 23, 2016; Published April 25, 2016)

Keywords: electronic materials, joining, fracture, flexible printed circuit board (FPCB), thermo-compression (TC) bonding

\section{Introduction}

Interconnection technology for joining the metallic pads of flexible printed circuit boards (FPCBs) to the outer leads of components, modules, displays, and rigid printed circuit boards (RPCBs), is of increasing importance in the electronics industry. ${ }^{1-4)}$ FPCBs can be applied to various electronic products, such as portable electronics and display modules etc., due to their many advantageous properties including lightness, small thickness, high glass transition temperature, and superior flexibility. ${ }^{5-9)}$ On the other hand, RPCBs have a low cost, high packaging density, and considerably better established reliability data. Recently, electronics manufacturers have shown increasing interest in the development of electrical and mechanical bonding techniques of electrodes, between FPCBs and RPCBs.

Various bonding methods, such as mechanical connecting, thermo-compression (TC) bonding, adhesive bonding, and ultrasonic bonding, have been used to bond electrodes between FPCBs and RPCBs. ${ }^{1,2)}$ Of these bonding methods, mechanical connections, using a connector, have been widely used due to their advantageous simplicity, low-cost, and high reliability. In spite of this, mechanical connections continue to have some problems, such as large volumes, difficult automation processes, and limited input/output (I/O) counts. TC bonding, with a solder alloy, could be one of the most suitable FPCB-RPCB bonding methods, because of its expected improved reliability and easy practical process (Fig. 1). The TC bonding method is a stable and well-controlled process that can produce robust and reliable connections. ${ }^{3,10-13)}$

In our previous study, we successfully accomplished TC bonding of a reliable FPCB-RPCB joint by using an Sn-Ag-

\footnotetext{
*Corresponding author, E-mail: jwyoon@kitech.re.kr, sbjung@skku.edu
}

$\mathrm{Cu}$ interlayer. ${ }^{10)}$ The aim of this current study is to investigate the hygrothermal reliability of TC bonded FPCB-RPCB joints. The relationship between the temperature-humidity (TH) test and joint mechanical reliability are presented in this paper.

\section{Experimental procedures}

Figure 2 shows optical images of the RPCB and FPCB that

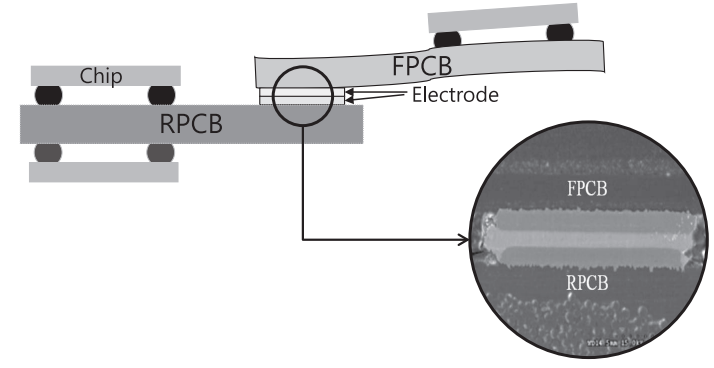

Fig. 1 Schematic of bonding of the electrodes between FPCB and RPCB.
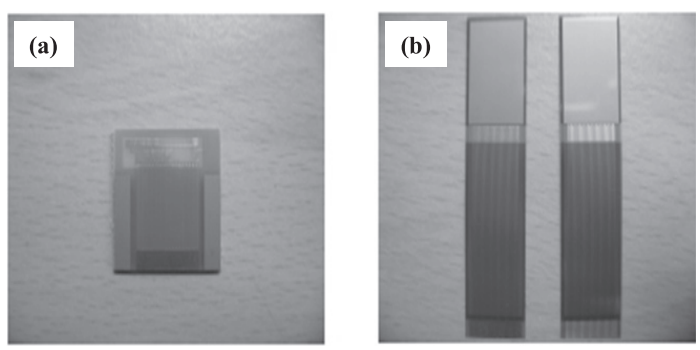

Fig. 2 Optical images of (a) RPCB and (b) FPCB used in this study. 
were used in this study. The FPCB and RPCB consisted of an $18 \mu$ m-thick polyimide and a $1 \mathrm{~mm}$-thick flame retardant 4 (FR-4) substrate, respectively. The $15 \mu$ m-thick Cu electrode of the RPCB was plated with an electroless nickel-immersion gold (ENIG) surface finish, and the thicknesses of the Ni and Au layers were $5 \mu \mathrm{m}$ and $0.05 \mu \mathrm{m}$, respectively. The FPCB had an electroless nickel-electroless palladium-immersion gold (ENEPIG) finished Cu electrode, and the thicknesses of the Ni, Pd, and Au layers were $5 \mu \mathrm{m}, 0.08 \mu \mathrm{m}$, and $0.03 \mu \mathrm{m}$, respectively. The pitch size and number of electrodes for the two PCBs (RPCB and FPCB) were $500 \mu \mathrm{m}$ and 25, respectively. The dimensions of the electrodes for both PCBs were $0.25 \times 2.7 \mathrm{~mm}^{2}$. The specifications of the PCBs used in this study are listed in Table 1. Pb-free $\mathrm{Sn}-3.0 \mathrm{Ag}-0.5 \mathrm{Cu}$ (in wt.\%) solder was used as an interlayer for TC bonding. The solder dipping process was used for the preparation of the $\mathrm{Sn}-\mathrm{Ag}-\mathrm{Cu}$ surface finish on the ENEPIG-plated $\mathrm{Cu}$ electrode of the FPCB. Solder dipping was performed at a dipping temperature of $260^{\circ} \mathrm{C}$ with a wetting balance tester (SAT-5100, Rhesca Co. Ltd., Japan). The average solder thickness after dipping was about $10 \sim 15 \mu \mathrm{m}$. Prior to TC bonding, the RPCB and FPCB were cleaned using a 10 vol. $\% \mathrm{H}_{2} \mathrm{SO}_{4}$ solution to remove the surface contaminants, and they were then dried with hot air. A TCW-215 (Avio, Japan) TC bonding machine was used in this study. The RPCB was fixed on an anvil, and the FPCB electrodes were bonded to the electrodes of the RPCB under optimum bonding conditions. The optimum bonding conditions were determined from our previous works $^{10)}$ and were as follows: a bonding temperature of $260^{\circ} \mathrm{C}$, a bonding pressure of $2.04 \mathrm{MPa}$, and a bonding time of $5 \mathrm{~s}$. In order to investigate the hygrothermal reliability of the TC bonded FPCB-RPCB joints, TH tests were performed. The FPCB-RPCB joints were bonded under optimum bonding conditions, and placed in a TH chamber (TSA-101S, ESPEC, Japan) controlled at $85^{\circ} \mathrm{C} / 85 \%$ relative humidity for up to $500 \mathrm{~h}$. After the hygrothermal reliability tests, the electrical resistance and peel strength of the bonded PCBs were measured. A total of 5 TC bonded FPCB-RPCB samples were tested at each condition, and the average values were reported. The electrical resistance of the samples were measured using a 2 point probe method. The displacement rate of the $90^{\circ}$ peel test was $0.1 \mathrm{~mm} / \mathrm{s}$. After bonding and peel testing, the interfaces and fracture surfaces were observed, and analyzed, using scanning electron microscopy (SEM, Hitachi S-3000H, Japan), energy dispersive X-ray spectroscopy (EDX), and X-ray photoelectron spectroscopy (XPS, ESCA 2000 LAB MK-II spectrometer, VG Microtech, England).

Table 1 Specifications of FPCB and RPCB used in this study.

\begin{tabular}{cc}
\hline Pitch size $(\mu \mathrm{m})$ & 500 \\
\hline $\begin{array}{c}\text { FPCB } \\
\begin{array}{c}\text { Electrode dimension } \\
\left(\mathrm{mm}^{2}\right)\end{array}\end{array}$ & $0.25 \times 2.7$ \\
\hline $\begin{array}{c}\text { Electrode number } \\
(\mathrm{ea})\end{array}$ & 25 \\
\hline Surface finish & FPCB ENEPIG $(5 \mu \mathrm{m} \mathrm{Ni} / 0.08 \mu \mathrm{m} \mathrm{Pd} / 0.03 \mu \mathrm{m} \mathrm{Au})$ \\
\cline { 2 - 3 } & RPCB $\quad \mathrm{ENIG}(5 \mu \mathrm{m} \mathrm{Ni} / 0.05 \mu \mathrm{m} \mathrm{Au})$ \\
\hline
\end{tabular}

\section{Results and Discussion}

Figure 3 shows the cross-sectional SEM image of the FPC$\mathrm{B}(\mathrm{ENEPIG}) / \mathrm{Sn}-3.0 \mathrm{Ag}-0.5 \mathrm{Cu} / \mathrm{RPCB}(\mathrm{ENIG})$ joint, bonded under optimum bonding conditions. Both interfaces of the FPCB-RPCB joint were very uniform and un-bonded interfaces were not observed at both interfaces.

Figure 4 shows the peel test results of the FPCB-RPCB joints that were exposed to $\mathrm{TH}$ treatment. The peel strength significantly decreased as $\mathrm{TH}$ time increased. In the case of the joint without the TH test $(0 \mathrm{~h})$, the peel strength was approximately $1.05 \mathrm{kgf} / \mathrm{cm}$. After $500 \mathrm{~h}$, the peel strength $(0.36 \mathrm{kgf} / \mathrm{cm})$ was reduced by around $70 \%$, due to a degradation of bonding strength (adhesion) between the polyimide and the $\mathrm{Cu}$ electrode of the FPCB, which will be discussed later.

We also investigated the effect of the high temperature storage (HTS) test on the reliability of TC bonded FPCB-RP$\mathrm{CB}$ joints, and the peel strength results ${ }^{10)}$ are used here to provide a direct comparison between the TH and HTS tests. The FPCB-RPCB joints were bonded under the same optimum bonding conditions $\left(260^{\circ} \mathrm{C}, 2.04 \mathrm{MPa}, 5 \mathrm{~s}\right)$, and then isothermally aged at 85 and $125^{\circ} \mathrm{C}$ for up to $500 \mathrm{~h}$. In the case of an aging temperature of $85^{\circ} \mathrm{C}$, a significant variation in

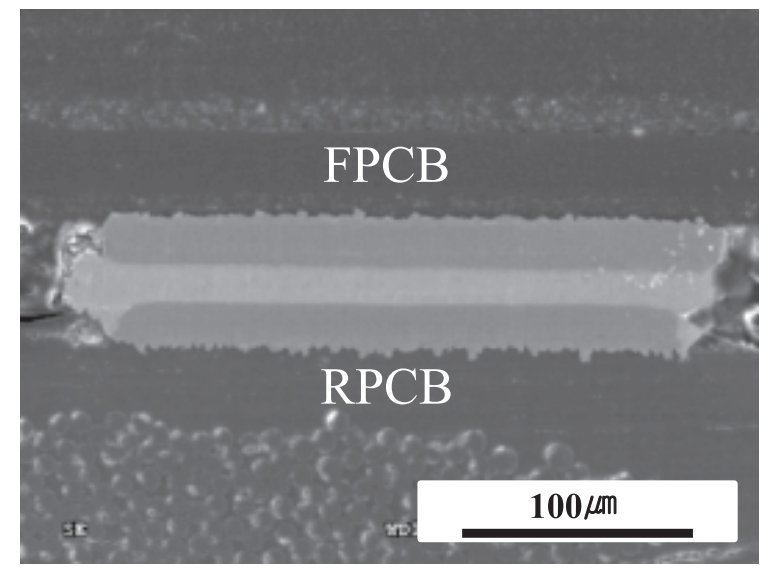

Fig. 3 Cross-sectional SEM image of the FPCB-RPCB interfaces bonded at $260^{\circ} \mathrm{C}$ for $5 \mathrm{~s}$ under bonding pressure of $2.04 \mathrm{MPa}$.

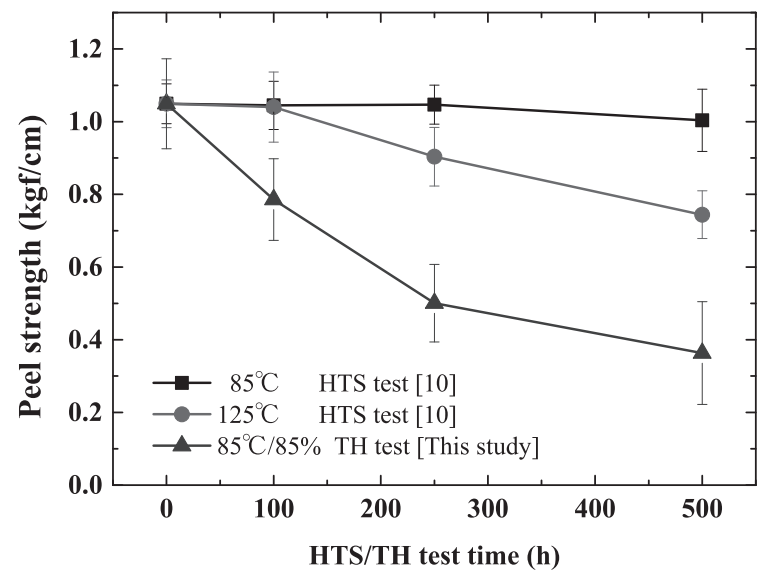

Fig. 4 Peel strength of FPCB-RPCB joints after $85^{\circ} \mathrm{C} / 85 \% \mathrm{TH}$ testing [this study] and HTS testing ${ }^{10)}$. 


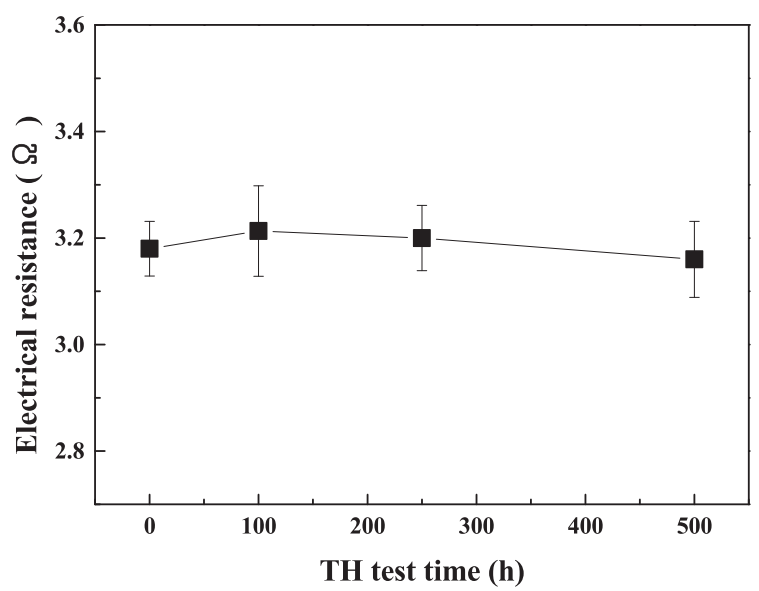

Fig. 5 Electrical resistance variation of FPCB-RPCB joints after $85^{\circ} \mathrm{C} / 85 \%$ TH testing.

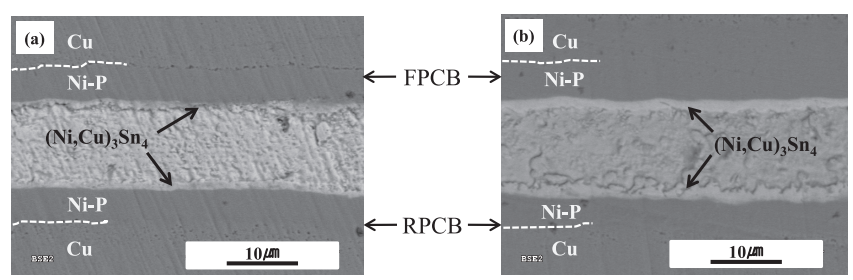

Fig. 6 Cross-sectional SEM images of FPCB-RPCB interfaces: (a) as-bonded joint and (b) after $85^{\circ} \mathrm{C} / 85 \% \mathrm{TH}$ testing for $500 \mathrm{~h}$.

peel strength was not observed after isothermal aging. In contrast, in the case of an aging temperature of $125^{\circ} \mathrm{C}$, the peel strength decreased as aging time increased. After $500 \mathrm{~h}$, the peel strength was reduced by about $30 \%$. When comparing TH and HTS tests, the TH test significantly deteriorated the integrity of the TC bonded FPCB-RPCB joints. This means that the combined effect of temperature and humidity on the $\mathrm{TH}$ test, rapidly damaged and deteriorated the FPCB-RPCB joints, compared to the temperature effect on the HTS test.

Figure 5 shows the variation of the electrical resistance of the joints with TH treatment. Generally, an abrupt increase in the electrical resistance of bonded joints means that complete failure occurred. However, a significant variation in electrical resistance of the $\mathrm{TH}$ tested joints was not observed. This means that the failures did not occur in the joints during the TH test. In addition, the 2 point probe method was used to measure the electrical resistance of the samples in this study, although the method is not sufficiently sensitive to detect changes in the resistance that are associated with degradation of the interconnections. If there were large accumulated damages in the interconnections, we observed an increase in the electrical resistance. In reality, we could not observe the large structural damages, or cracks in the interconnections in the cross-sectional samples. Therefore, a significant increase in resistance was not observed in this study, and the electrical resistance values existed in error ranges, as shown in Fig. 5. Nevertheless, we measured the electrical resistance of the joints using the 2 point probe method to detect catastrophic failure in the TC bonded FPCB-RPCB joints after the TH test.

Figure 6 shows the cross-sectional SEM images of the FPCB-RPCB joints, before and after TH treatments. In the case
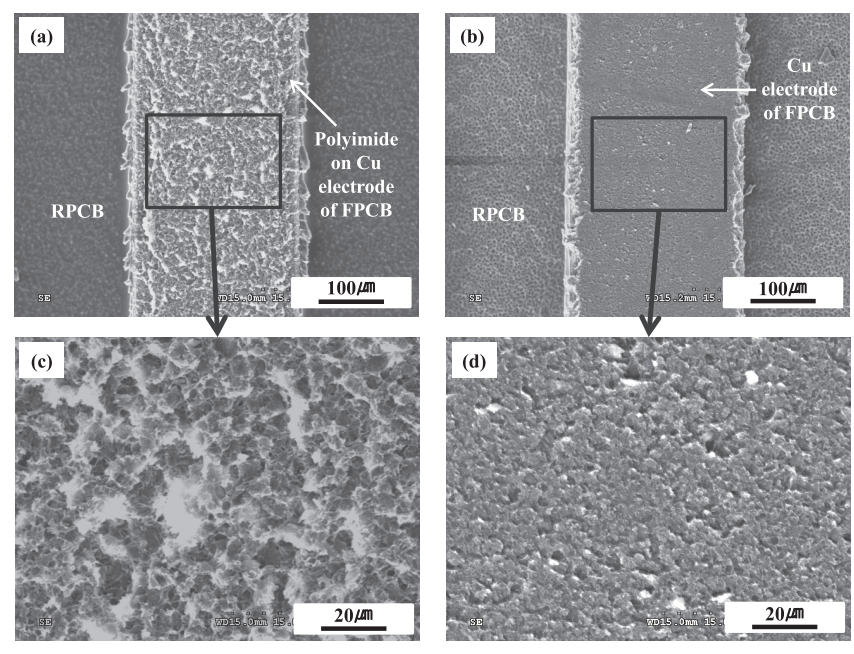

Fig. 7 Fracture surfaces of the FPCB-RPCB joints after $85^{\circ} \mathrm{C} / 85 \%$ TH test followed by a $90^{\circ}$ peel test; (a), (c) $0 \mathrm{~h}$ and (b), (d) $500 \mathrm{~h}$.

of the as-bonded joint, thin $(\mathrm{Ni}, \mathrm{Cu})_{3} \mathrm{Sn}_{4}$ intermetallic compounds (IMCs) formed at both interfaces, as shown in Fig. 6(a). The upper FPCB interface underwent 2 reflow processes. The first was the dipping process for the $\mathrm{Sn}-\mathrm{Ag}-\mathrm{Cu}$ surface finish on the ENEPIG-plated $\mathrm{Cu}$ electrode of the FPCB. The second was the TC bonding process. In contrast, the lower RPCB interface was first reflowed in the TC bonding process. It is known that the Au and Pd layers in the ENEPIG system very quickly dissolve into the molten solder. ${ }^{14,15)}$ Therefore, the topmost Au and Pd layers for the FPCB (ENEPIG) were dissolved in the molten solder during the initial dipping process, leaving the electroless $\mathrm{Ni}(\mathrm{P})$ layer exposed to the molten solder. On the other hand, during TC bonding, the topmost Au layer for the RPCB (ENIG) dissolved in the molten solder during the short bonding time, leaving the electroless $\mathrm{Ni}(\mathrm{P})$ layer exposed to the molten solder. Consequent$\mathrm{ly}$, in this study, the reactions between the molten $\mathrm{Sn}-\mathrm{Ag}-\mathrm{Cu}$ solder and the electroless $\mathrm{Ni}(\mathrm{P})$ layer resulted in the formation of $(\mathrm{Ni}, \mathrm{Cu})_{3} \mathrm{Sn}_{4}$ IMCs at both interfaces, as shown in Fig. 6(a). After TH testing for $500 \mathrm{~h}$, the thickness of the IMC layer slightly increased, as shown in Fig. 6(b).

Fracture analyses were performed to elucidate the reason for the decrease in peel strength that occurred with TH test time, as shown in Fig. 4. Figure 7 shows the fracture surfaces of the FPCB-RPCB joint after TH testing, followed by a peel test. In the case of the joint without the TH test, fracture occurred at the polyimide on the $\mathrm{Cu}$ electrode of the FPCB, as shown in Figs. 7(a) and 7(c). This means that the adhesion strengths for both solder interfaces were higher than that of the polyimide of the FPCB. We observed the presence of the polyimide on the fracture surface, and that the fracture surface was very rough. Markedly different fracture surfaces were observed from the TH tested joints. After the TH test for $500 \mathrm{~h}$, a fracture occurred at the interface between the polyimide and $\mathrm{Cu}$ electrodes in the FPCB, as shown in Figs. 7(b) and 7(d). We observed the $\mathrm{Cu}$ electrode of the FPCB on the fracture surface (Fig. 7(b)), which implies that the fracture occurred at the $\mathrm{Cu}$ electrode/polyimide interface on the FPCB side. These observations from Fig. 7 could explain the variations in peel strength with the TH test, as shown in 
Fig. 4.

XPS analysis was conducted to investigate the chemical bonding state of the peeled FPCB surface. Figure 8 shows the XPS results of the $C_{1 s}$ spectra for the fractured FPCB surfaces after the peel test. The $0 \mathrm{~h} \mathrm{TH}$ test sample had a C-C ratio of $70.37 \%$, a $\mathrm{C}-\mathrm{N}$ ratio of $19.86 \%$, a $\mathrm{C}=\mathrm{O}$ ratio of $3.92 \%$ and a $\mathrm{C}-\mathrm{O}$ ratio of $5.857 \%$. On the other hand, the $500 \mathrm{~h} \mathrm{TH}$ test sample had a C-C ratio of $79.19 \%$, a C-N ratio of $16.84 \%$ and a C-O ratio of $3.97 \%$. After $\mathrm{TH}$ testing, the ratio of $\mathrm{C}-\mathrm{N}$ bonds slightly decreased, while the $\mathrm{C}-\mathrm{C}$ ratio increased, as shown in Fig. 8. In contrast, the ratio of $\mathrm{C}-\mathrm{O}$ bonds decreased after the $\mathrm{TH}$ test. In addition, $\mathrm{C}=\mathrm{O}$ bonding was not observed after $\mathrm{TH}$ test.

Previous studies reported that suitable functional groups, such as hydroxyl $(-\mathrm{OH})$, carbonyl $(\mathrm{C}=\mathrm{O})$, and carboxyl $(\mathrm{COOH})$ species, promoted the adhesion strength at the interface between metal and polymer. ${ }^{16,17)}$ It was also reported that the adhesion of metals to polyimides occurs through the formation of metal-O complexes, or metal oxides at the interface through the reaction of metal with the pendent oxygen atoms in the polyimide. ${ }^{18,19)}$ Therefore, in this study, the chemical bonding states were changed due to the humidity absorption into the FPCB, during TH testing, decreasing the

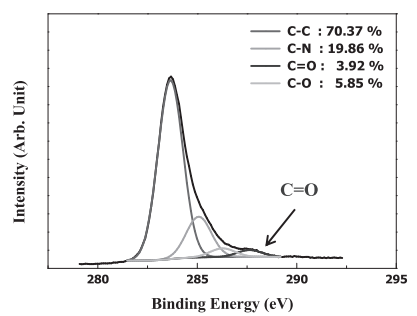

(a)

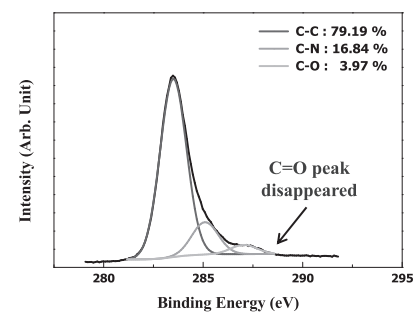

Fig. 8 XPS results for C1s spectra of the fractured FPCB surfaces: (a) $0 \mathrm{~h}$ and (b) $85^{\circ} \mathrm{C} / 85 \% 500 \mathrm{~h}$. ratios of $\mathrm{C}-\mathrm{O}$ and $\mathrm{C}=\mathrm{O}$ bonds. These results suggest that the decrease in $\mathrm{C}-\mathrm{O}$ and $\mathrm{C}=\mathrm{O}$ ratios decreased the adhesion strengths between the $\mathrm{Cu}$ layer and polyimide. In other words, the decrease in the functional groups identified as $\mathrm{C}-\mathrm{O}$ and $\mathrm{C}=\mathrm{O}$ bonds may have contributed to the deteriorated chemical interactions between $\mathrm{Cu}$ and polyimide surfaces, thereby decreasing the measured peel strength. As a result, the XPS results revealed that the $\mathrm{FPCB}$ with higher $\mathrm{C}-\mathrm{O}$ and $\mathrm{C}=\mathrm{O}$ ratios experienced higher peel strength.

Figure 9 shows schematics of the fracture mode transitions of the FPCB-RPCB joint before and after the TH [this study] and HTS $^{10)}$ tests. In the case of the joint in which the reliability test was not performed, a fracture occurred at the polyimide of the FPCB. On the other hand, after the TH test, a fracture occurred at the polyimide/ $\mathrm{Cu}$ electrode interface of the FPCB (Fig. 9(a)). This was due to the humidity absorption into the FPCB, which resulted in the degradation of bonding strength between the polyimide and $\mathrm{Cu}$ electrodes. After the HTS test at $125^{\circ} \mathrm{C}$, brittle interfaces formed along the solder joint on the PCB side, resulting in the switching of the failure mode from a polyimide-electrode failure to a brittle IMC failure (Fig. 9(b)).

It is generally known that the mechanical reliability of solder joints is very sensitive to the thickness of the interfacial IMC layer. ${ }^{20-24)}$ However, in this current study, thin $(\sim 2 \mu \mathrm{m})$ and uniform IMC layers formed at both interfaces, in spite of the $\mathrm{TH}$ test for $500 \mathrm{~h}$ (Fig. 6). Therefore, the fracture did not occur at the solder/PCB interface after the TH test.

\section{Conclusions}

In this study, we focused on the evaluation of the hygrothermal reliability of thermo-compression bonded FPCB-RP$\mathrm{CB}$ joints. Firstly, we successfully performed the TC bonding of reliable FPCB(ENEPIG)-RPCB(ENIG) joints, by using an $\mathrm{Sn}-\mathrm{Ag}-\mathrm{Cu}$ interlayer. We then performed a TH test followed

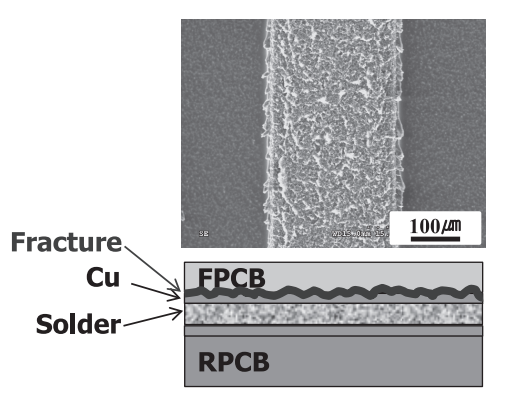

before reliability test (a)

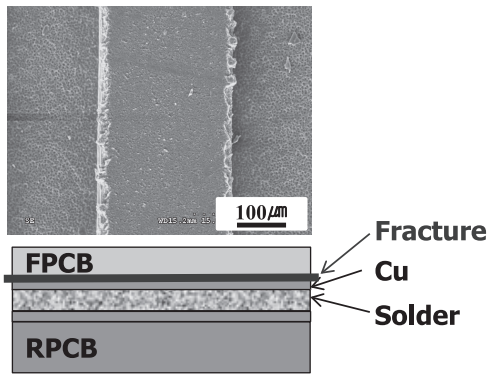

(b)

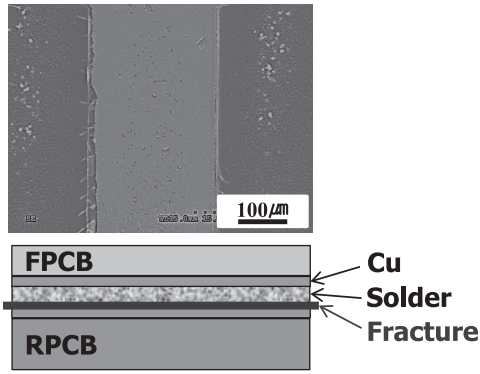

after reliability test

Fig. 9 Schematics of fracture mode transitions after reliability testing; (a) TH test and (b) HTS test. 
by peel tests. The peel strength significantly decreased, as TH time increased. However, a significant variation in electrical resistance for $\mathrm{TH}$ tested joints was not observed. Thin and uniform $(\mathrm{Ni}, \mathrm{Cu})_{3} \mathrm{Sn}_{4}$ IMC layers formed at both ENENIG/ Sn-3.0Ag-0.5Cu/ENIG interfaces, regardless of the TH test. After a TH test for $500 \mathrm{~h}$, the thickness of the IMC layer was increased slightly. In the case of the joint without the TH test, a fracture occurred at the polyimide on the $\mathrm{Cu}$ electrode of the FPCB. After the TH test, the degradation of the polyimide/ $\mathrm{Cu}$ interface in the FPCB occurred due to hygrothermal treatment, resulting in the switching of the failure mode from a polyimide failure to a brittle polyimide/Cu interface failure. The solder interfaces (IMC layers), which are generally known to be brittle in the solder joints, did not affect the hygrothermal reliability of the joints during the TH testing. When comparing the TH and HTS tests, the TH test significantly deteriorated the mechanical integrity of the TC bonded FPCB-RPCB joints. The decrease in $\mathrm{C}-\mathrm{O}$ and $\mathrm{C}=\mathrm{O}$ bond ratios contributed to the deteriorated chemical interactions between $\mathrm{Cu}$ and polyimide surfaces, thereby decreasing the measured peel strength after TH testing. These results clearly indicated that the durability of the FPCB in temperature and humidity testing is very important in terms of the long-term reliability of the TC bonded FPCB-RPCB joints.

\section{REFERENCES}

1) K.S. Kim, J.P. Jung and Y.N. Zhou: Solder. Surf. Mt. Technol. 21 (2009) 4-10.

2) J.B. Lee, J.M. Koo, S.M. Hong, H.Y. Shin, Y.J. Moon, J.P. Jung, C.D. Yoo and S.B. Jung: Jpn. J. Appl. Phys. 47 (2008) 4300-4304.

3) J. W. Yoon, J. K. Jang, J. H. Choi, J. G. Lee, J. B. Lee, B. I. Noh, and S.
B. Jung: in Proceedings of the 12th Electronics Packaging Technology Conference, Singapore, 2010, P. 811.

4) J.W. Yoon, J.G. Lee, J.B. Lee, B.I. Noh and S.B. Jung: J. Mater. Sci Mater. Electron. 23 (2012) 41-47.

5) F. Barlow, A. Lostetter and A. Elshabini: Microelectron. Reliab. 42 (2002) 1091-1099.

6) A. Bozkurt and A. Lal: Sens. Actuators A Phys. 169 (2011) 89-97.

7) I.H. Kazi, P.M. Wild, T.N. Moore and M. Sayer: Thin Solid Films 515 (2006) 2602-2606.

8) B.I. Noh, J.W. Yoon, J.H. Choi and S.B. Jung: Mater. Trans. 51 (2010) 85-89.

9) T. Aizawa, K. Okagawa and M. Kashani: J. Mater. Process. Technol. 213 (2013) 1095-1102.

10) J.W. Yoon, M.K. Ko, B.I. Noh and S.B. Jung: Microelectron. Reliab. 53 (2013) 2036-2042.

11) S.E. Kim and S. Kim: Microelectron. Eng. 137 (2015) 158-163.

12) C.S. Tan, D.F. Lim, X.F. Ang, J. Wei and K.C. Leong: Microelectron. Reliab. 52 (2012) 321-324.

13) Z. Huang, R.E. Jones and A. Jain: Microelectron. Eng. 122 (2014) 4651.

14) J.W. Yoon, B.I. Noh, J.H. Yoon, H.B. Kang and S.B. Jung: J. Alloy. Compd. 509 (2011) L153-L156.

15) S.P. Peng, W.H. Wu, C.E. Ho and Y.M. Huang: J. Alloy. Compd. 493 (2010) 431-437.

16) S.H. Kim, S.W. Na, N.E. Lee, Y.W. Nam and Y.H. Kim: Surf. Coat. Tech. 200 (2005) 2072-2079.

17) J.S. Eom and S.H. Kim: Thin Solid Films 516 (2008) 4530-4534.

18) R. Haight, R.C. White, B.D. Silverman and P.S. Ho: J. Vac. Sci. Technol. A 6 (1988) 2188-2199.

19) N.J. Chou, D.W. Dong, J. Kim and A.C. Liu: J. Electrochem. Soc. 131 (1984) 2335-2340.

20) J.W. Yoon, B.I. Noh and S.B. Jung: IEEE Trans. Compon. Packag. Technol. 33 (2010) 64-70.

21) J.W. Yoon and S.B. Jung: Mater. Sci. Technol. 25 (2009) 1478-1484.

22) S.S. Ha, J. Park and S.B. Jung: Mater. Trans. 52 (2011) 1553-1559.

23) J.W. Yoon, B.I. Noh and S.B. Jung: Met. Mater. -Int. 20 (2014) 515519.

24) F.X. Che and J.H.L. Pang: J. Alloy. Compd. 541 (2012) 6-13. 